\title{
LITERATUR REVIEW TERAPI NONFARMAKOLOGIS UNTUK MENGURANGI MUAL MUNTAH PADA IBU HAMIL
}

\section{${ }^{1}$ Ni Nyoman Yeyen Abriyani, ${ }^{2}$ Marsela Renasari Presty dan ${ }^{3}$ Ayu Kurniati}

\author{
Akademi Kebidanan Panca Bhakti Pontianak \\ Email korespondensi: jejeabriyani05@gmail.com,ayukurniati67@gmail.com
}

\begin{abstract}
Abstrak
Hampir 70\% wanita di seluruh dunia memiliki pengalaman mual muntah selama kehamilan. Mual, muntah pada kehamilan menyebabkan penurunan kualitas hidup, dan memiliki efek buruk pada fungsi kehidupan sosial, pekerjaan, dan kehidupan rumah tangga. Mengobati mual muntah selama kehamilan terus menjadi tantangan bagi ibu hamil dan petugas kesehatan. Meskipun ringan dan dapat di tangani, mual dapat berkembang menjadi kondisi yang mengancam ibu dan bayi. Akan lebih baik jika ibu hamil mampu mengatasi masalah mual pada awal kehamilan dengan menggunakan terapi non farmakologis. Terapi non farmakologis bersifat noninstruktif, noninfasif, murah, sederhana, efektif dan tanpa efek samping yang merugikan. Tujuan dari penelitian ini adalah untuk mengetahui terapi non farmakologis yang dapat di berikan pada ibu hamil untuk mengurangi mual muntah pada ibu hamil. Metode penelitian yang di gunakan dalam penelitian ini adalah literartur review. Pencarian studi yang relevan dengan topik dengan hasil akhir 10 artikel yang digunakan. Menurut hasil review literatur, sebagian besar terapi nonfarmakologis efektif dalam mengurangi mual muntah dalam kehamilan, di antaranya jahe, aroma terapi lemon, mint dan sirup delima dapat direkomendasikan untuk mengurangi mual muntah dalam kehamilan.
\end{abstract}

Kata kunci: terapi nonfarmakologis, mual, muntah, ibu hamil

\begin{abstract}
Nearly $70 \%$ of women worldwide have experience of nausea and vomiting during pregnancy. Nausea, releases on the effects that cause a decrease in quality of life, and has effects on social functions, work, and household life. Treating nausea and vomiting during pregnancy continues to be a challenge for pregnant women and health workers. Although light and treatable, babies can develop into developing mothers. It would be better if pregnant women can overcome the problem of nausea in early pregnancy by using non-pharmacological therapy. Non-pharmacological therapies are noninstructive, non-invasive, inexpensive, simple, effective and without adverse side effects. The purpose of this study is to study non-pharmacological therapies that can be given to pregnant women to replace nausea and vomiting in pregnant women. The research method used in this research is Literature Review. Search for studies relevant to the topic with the end of result are 10 articles used. According to the results of the literature review, most nonpharmacologic therapies are effective in reducing nausea and vomiting in the assessment, overcome ginger, aroma therapy of lemon, mint and pomegranate syrup can be recommended to reduce nausea and vomiting in pregnancy.
\end{abstract}

Keywords: nonpharmacological thearpy, nausea, vomiting, pregnant women

\section{Pendahuluan}

Hampir 70\% wanita di seluruh dunia memiliki pengalaman mual muntah selama kehamilan (Einarson et al., 2013). Mual dan muntah mempengaruhi sebanyak $80 \%$ wanita hamil dan merupakan salah satu alasan paling umum mereka ke rumah sakit (Wise, 2016).

\footnotetext{
${ }^{1}$ STIKes Nusantara Kupang

${ }^{2}$ Akademi Kebidanan Panca Bhakti Pontianak

${ }^{3}$ Universitas 'Aisyiyah Yogyakarta
}

Beberapa gejala sangat parah sehingga perempuan menderita dan dapat mengancam jiwa dengan gejala dehidrasi dan ketidakseimbangan elektrolit dikenal sebagai hiperemesis gravidarum (HG) (Clark et al., 2012) .Hiperemesis gravidarum mempengaruhi $1-3 \%$ dari kehamilan 
perempuan dan pedoman mengatakan bahwa ini dapat didiagnosis mual dan muntah yang berkepanjangan dikaitkan dengan tiga gejala: penurunan berat badan lebih dari 5\% sebelum kehamilan berat badan, dehidrasi, dan ketidakseimbangan elektrolit (Wise, 2016).

Gejala muncul antara usia kehamilan 47 minggu, yaitu keparahan puncak untuk hiperemesis adalah sekitar 11 minggu dengan 90\% kasus berakhir pada usia kehamilan 20 minggu (NICE 2013; Bottomley 2009). Mual dan muntah pada kehamilan terjadi karena pengaruh hCG, penurunan tonus otot-otot traktus digestivus sehingga seluruh traktus digestivus mengalami penurunan kemampuan bergerak (Kusmiyati, 2015). Mual, muntah pada kehamilan menyebabkan penurunan kualitas hidup, dan memiliki efek buruk pada fungsi kehidupan sosial, pekerjaan, dan kehidupan rumah tangga (Wood et al., 2013). Efek Mual muntah diperkuat dengan peningkatan keparahan gejala Mual, muntah. Selain itu, peningkatan risiko komorbiditas, terutama dengan perasaan depresi, mulas dan masalah refluks (Heitmann et al., 2015) yang menimbulkan beban yang lebih besar pada wanita.

wanita mengalami mual muntah saat kehamilan dan muntah lebih tinggi kemungkinan mengembangkan komplikasi kehamilan (Chortatos et al., 2013). Mengobati mual muntah selama kehamilan terus menjadi tantangan bagi ibu hamil dan petugas kesehatan. Meskipun ringan dan dapat di tangani, mual dapat berkembang menjadi kondisi yang mengancam ibu dan bayi (Childbirth Education, 2017).

Banyak ibu hamil yang menggunakan terapi komplementer dengan perkiraaan 35\% menggunakan obat herbal saat hamil(Frawley et al., 2015), (Holden et al., 2015). Terapi kompleter merupakn salah satu terapi nonfarmakologis. Terapi non farmakologis bersifat noninstruktif, noninfasif, murah, sederhana, efektif dan tanpa efek samping yang merugikan (Iskandar, 2017). Tujuan dari penelitian ini adalah untuk mengetahui terapi non farmakologis yang dapat di berikan pada ibu hamil untuk mengurangi mual muntah pada ibu hamil.

\section{Metode}

Metode penelitian yang di gunakan dalam penelitian ini adalah literartur revie. pencarian studi yang relevan dengan topik dilakukan dengan menggunakan google scholar dan medline (pubmed) di batasi dari tahun 2010 sampai dengan tahun 2020. Keyword yang di gunakan dalam pencarian literatur adalah complementary, non pharmacology, herbal, nausea, vomiting, emesis, pregnancy, pregnant women, ginger, aroma therapy. Kriteria inklusi dan eksklusi review artikel dalam penelitian ini: 


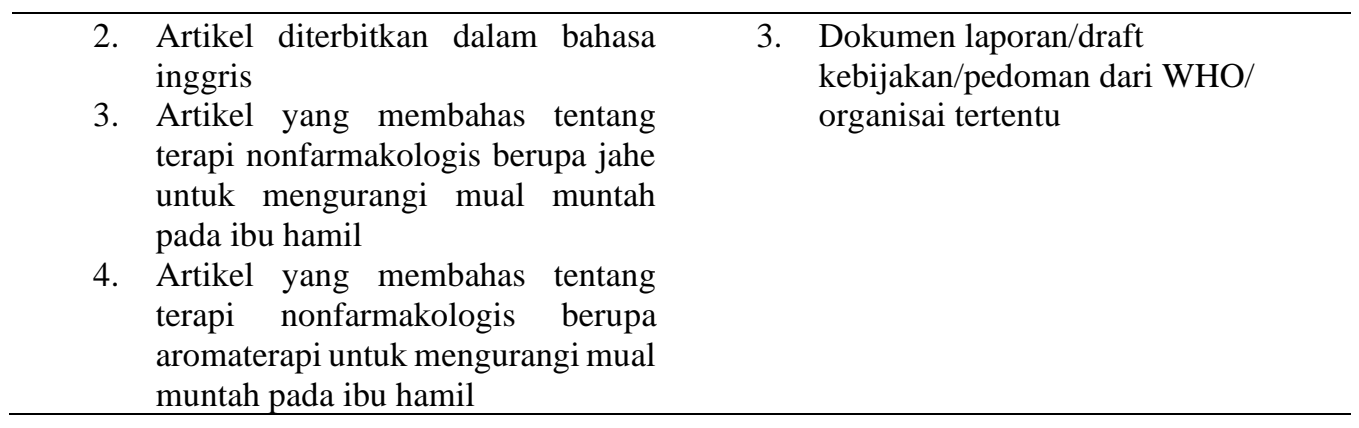

\section{Hasil dan Pembahasan}

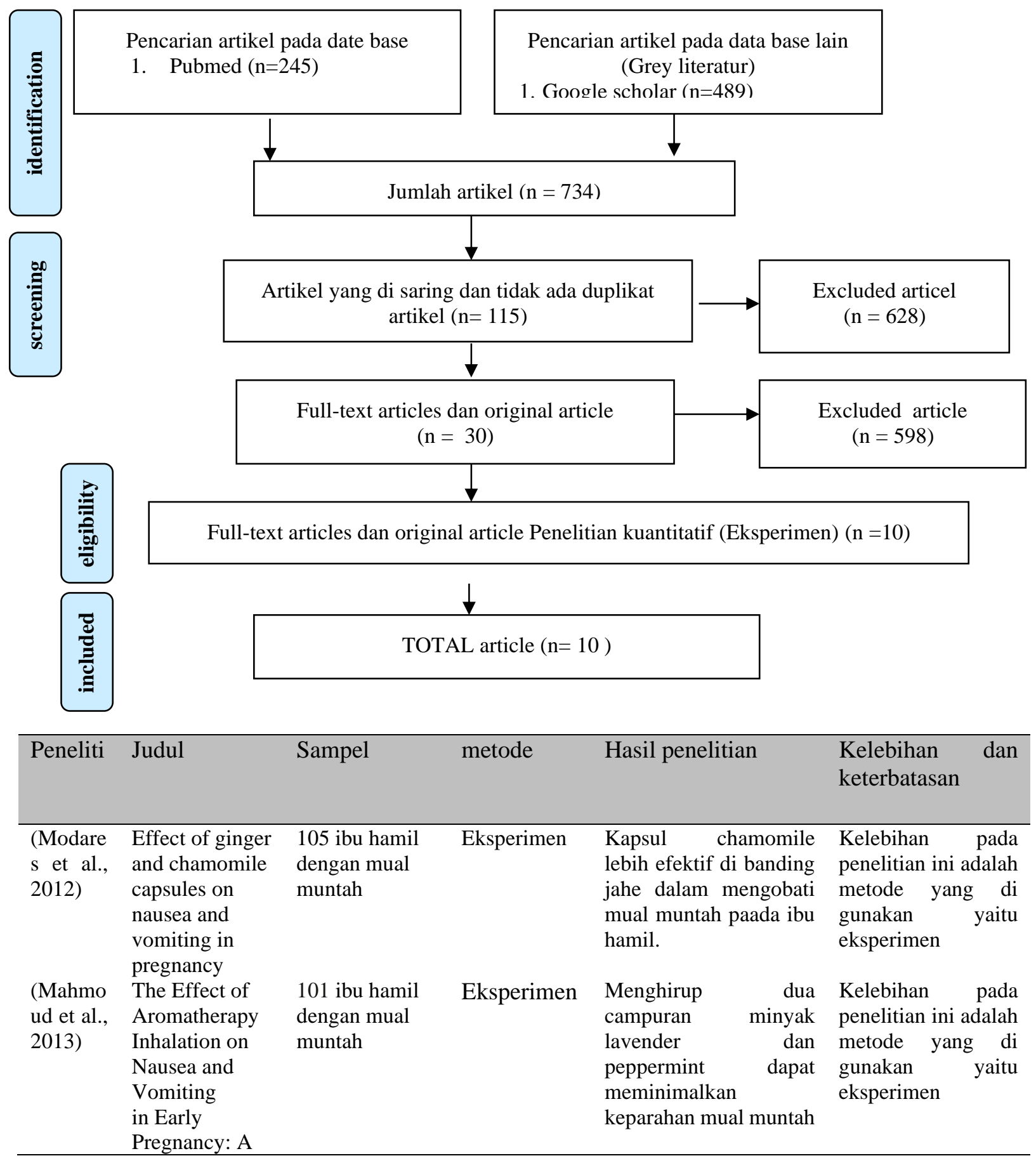




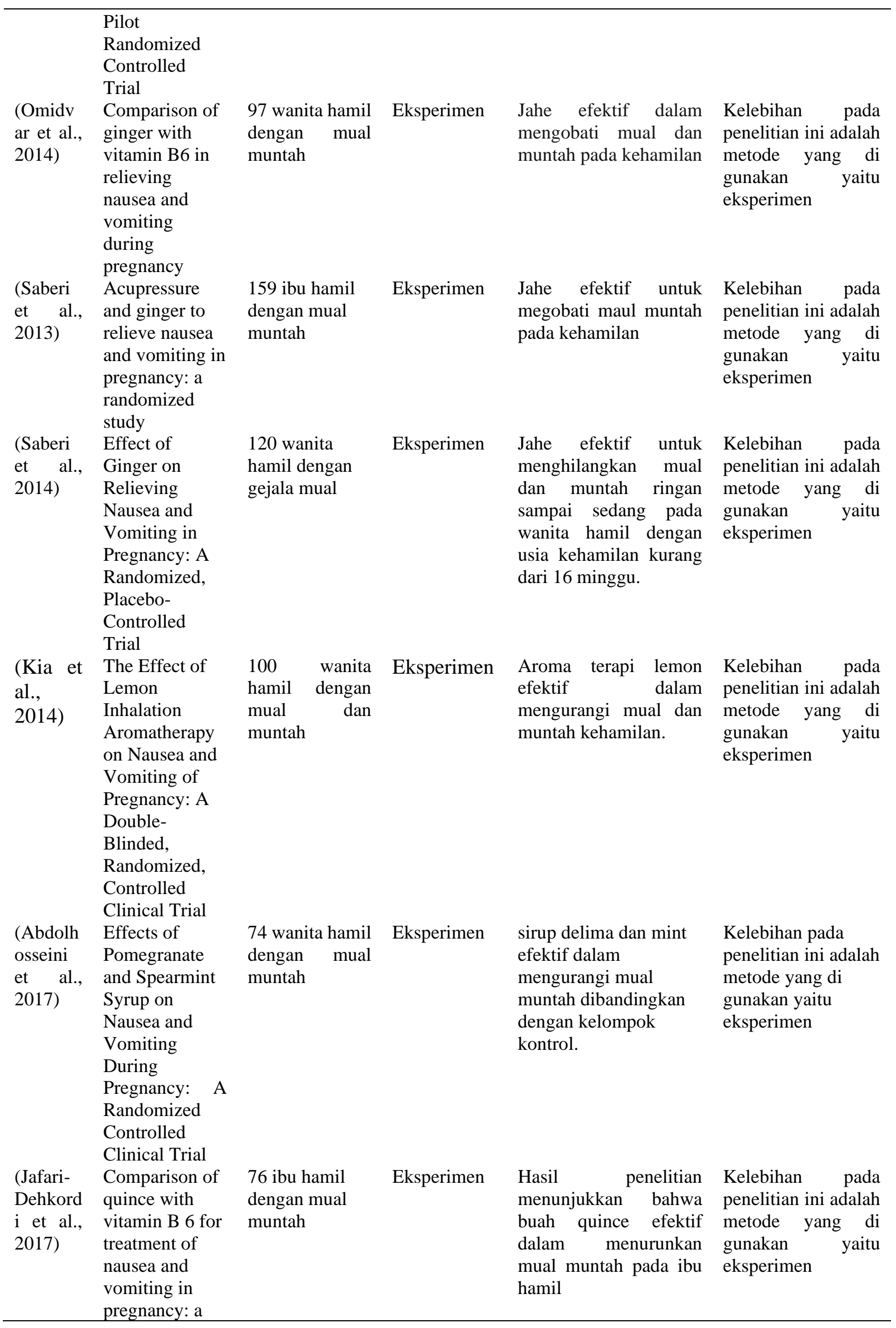




\begin{tabular}{|c|c|c|c|c|c|}
\hline & $\begin{array}{l}\text { randomised } \\
\text { clinical trial. }\end{array}$ & & & & \\
\hline $\begin{array}{l}\text { (Sharifz } \\
\text { adeh et } \\
\text { al., } \\
\text { 2018) }\end{array}$ & $\begin{array}{l}\text { A comparison } \\
\text { between the } \\
\text { effects of } \\
\text { ginger, } \\
\text { pyridoxine } \\
\text { (vitamin B6) } \\
\text { and placebo for } \\
\text { the treatment of } \\
\text { the first } \\
\text { trimester } \\
\text { nausea and } \\
\text { vomiting of } \\
\text { pregnancy } \\
\text { (NVP) }\end{array}$ & $\begin{array}{l}77 \text { ibu hamil } \\
\text { dengan mual } \\
\text { muntah }\end{array}$ & eksperimen & $\begin{array}{l}\text { Jahe lebih efektif dalam } \\
\text { mengurangi mual } \\
\text { muntah dalam } \\
\text { kehamilan }\end{array}$ & $\begin{array}{l}\text { Kelebihan pada } \\
\text { penelitian ini adalah } \\
\text { metode yang di } \\
\text { gunakan yaitu } \\
\text { eksperimen }\end{array}$ \\
\hline $\begin{array}{l}\text { (Joulaee } \\
\text { rad et } \\
\text { al., } \\
2018)\end{array}$ & $\begin{array}{l}\text { Effect of } \\
\text { aromatherapy } \\
\text { with papermint } \\
\text { oil on the } \\
\text { severity of } \\
\text { nausea and } \\
\text { vomiting in } \\
\text { pregnancy: a } \\
\text { single-blind, } \\
\text { randomized, } \\
\text { placebo- } \\
\text { controlled trial }\end{array}$ & $\begin{array}{l}56 \text { ibu hamil } \\
\text { dengan mual } \\
\text { muntah }\end{array}$ & eksperimen & $\begin{array}{l}\text { Hasil penelitian } \\
\text { menunjukkan bahwa } \\
\text { aromaterapi mint dan } \\
\text { plasebo sama-sama } \\
\text { dapat mengurangi mual } \\
\text { dan muntah. Kesamaan } \\
\text { ini bisa jadi karena } \\
\text { dampak psikologis dari } \\
\text { intervensi pada ibu } \\
\text { hamil. }\end{array}$ & $\begin{array}{l}\text { Kelebihan pada } \\
\text { penelitian ini adalah } \\
\text { metode yang di } \\
\text { gunakan yaitu } \\
\text { eksperimen }\end{array}$ \\
\hline
\end{tabular}

Mengobati mual muntah selama kehamilan terus menjadi tantangan bagi ibu hamil dan petugas kesehatan. Meskipun ringan dan dapat di tangani, mual dan muntah dapat berkembang menjadi kondisi yang mengancam ibu dan bayi. Penatalaksanaan mual muntah pada kehamilan yang efektif dapat membantu mengoptimalkan kesehatan ibu hamil dan janin selama kehamilan. Akan lebih baik jika ibu hamil mampu mengatasi masalah mual muntah pada awal kehamilan dengan menggunakan terapi non farmakologis (Childbirth Education, 2017). Terapi non farmakologis bersifat noninstruktif, noninfasif, murah, sederhana, efektif dan tanpa efek samping yang merugikan. Dengan demikian, muntah pada kehamilan perlu diatasi salah satunya dengan herbal atau terapi nonfarmakologis (Iskandar, 2017). Berdasarkan hasil study puskata, sebagian besar penelitian tentang terapi nonfarmakologis seperti jahe, aroma terapi lemon, mint dan sirup buah delima efektif dalam mengurangi mual muntah dalam kehamilan.

\section{Penggunaan inhalasi lemon efektif} untuk mengurangi mual dan muntah selama kehamilan (Kia et al., 2014). Penurunan frekuensi mual muntah pada kehamilan menggunakan aromatherapy mampu menurunkan skor frekuensi mual muntah pada kehamilan karena baunya yang segar dan membantu memperbaiki atau menjaga kesehatan, membangkitkan semangat gairah, 
menyegarkan serta menenangkan jiwa dan merangsang proses penyembuhan. Molekul dalam aromaterapi ketika dihirup melalui rongga hidung dapat merangsang sistem limbik di otak. Sistem limbik di otak merupakan area yang memengaruhi emosi dan memori serta secara langsung terkait dengan adrenalin, kelenjar hipofisis, hipotalamus, bagian-bagian tubuh yang mengatur denyut jantung, tekanan darah, stres, keseimbangan tubuh dan pernafasan (Runiari, 2010).

Penggunaan aromaterapi papermint efektif untuk mengurangi mual dan muntah selama kehamilan (Joulaeerad et al., 2018), (Abdolhosseini et al., 2017). Papermint juga bertindak sebagai anastesi pada dinding perut yang berhenti mual dan muntah (Ahmed et al., 2012). Mint adalah ramuan obat terkenal dan penting yang digunakan sebagai peredam mual pasca operasi juga sebagai agen antiseptik, analgesik, dan anticlotting di Indonesia obat-obatan. Satu mekanisme yang diusulkan untuk anti emetik dan efek antispasmodik pada sistem pencernaan adalah penghambatan kontraksi otot yang diinduksi serotonin. Peppermint juga bertindak sebagai obat bius pada dinding perut yang menghentikan mual dan muntah (Stea, 2012).

Penggunaan jahe efektif untuk mengurangi mual dan muntah selama kehamilan (Omidvar et al., 2014), (Saberi et al., 2013), (Sharifzadeh et al., 2018). Jahe memblokir reseptor serotonin dan diinduksi antiemetik efek di pencernaan dan pusat gugup sistem. Kondisi ini menjelaskan mengapa jahe bisa mengurangi mual dan muntah dalam kehamilan. Senyawa fitokimia dari jahe seperti jahe aku, shogaol dan zingerone menyediakan farmakologis dan efek fisiologis seperti antioksidan, antiinflamasi, analgesik, anti-karsinogenik, tidak beracun dan non-mutagenik (Wiraharja et al., 2011).

Penggunaan buah delima yang di kemas dalam bentuk sirup efektif untuk mengurangi mual dan muntah selama kehamilan (Abdolhosseini et al., 2017). Delima dengan anti- H. pylori dan aktivitas antiulcer, telah digunakan sebagai tonik lambung. Selanjutnya, suplementasi makanan ibu dengan jus delima selama kehamilan mengurangi apoptosis yang diinduksi stimulus, stres oksidatif plasenta dan kejadian disfungsi plasenta pada kehamilan (Chen, 2012).

Penggunaan Kapsul chamomile yang di kemas dalam bentuk kapsul efektif untuk mengurangi mual dan muntah selama kehamilan (Modares et al., 2012). Obatnya biasanya diekstrak dari bunga kering chamomile menggunakan air, etanol atau metanol sebagai pelarut dan hasil ekstrak dikenal dengan ekstrak air, etanol (alkohol) dan / atau metanol. Ekstrak chamomile mengandung sekitar 50 persen alkohol. Ekstrak chamomile mengandung $1.2 \%$ apigenin yang merupakan salah satu agen bioaktif paling efektif. Flavonoid apigenin dan luteolin memiliki sifat antiinflamasi, karminatif dan antispasmodik properti. Apigenin mengikat reseptor GABA dan memiliki efek sedatif ringan. Coumarin 
umbelliferone adalah dilaporkan antispasmodik, antibakteri dan antijamur. Dalam ramuan herbal mengandung anti spasmodik dan memperbaiki sistem pencernaan (Srivastava, 2011).

\section{Kesimpulan}

Menurut hasil review literatur, sebagian besar terapi nonfarmakologis efektif dalam mengurangi mual muntah dalam kehamilan, di antaranya jahe, aroma terapi lemon, mint dan sirup delima, chamomile dapat direkomendasikan untuk mengurangi mual muntah dalam kehamilan.

\section{Referensi}

Abdolhosseini, S., Hashem-Dabaghian, F., Mokaberinejad, R., Sadeghpour, O., \& Mehrabani, M. (2017). Effects of pomegranate and spearmint syrup on nausea and vomiting during pregnancy: A randomized controlled clinical trial. Iranian Red Crescent Medical Journal, 19(10). https://doi.org/10.5812/ircmj.13542

Ahmed, E. M. S., Soliman, S. M., \& Mahmoud, H. M. (2012). Effect of Peppermint as One of Carminatives on Relieving Gastroesophageal Reflux Disease ( GERD ) During Pregnancy. $8(4)$.

Childbirth Education. (2017). International Journal of Childbirth Education, 32(1), $1-50$.

Chortatos, A., Haugen, M., Iversen, P. O., Vikanes, A., Magnus, P., \& Veierød, M. B. (2013). Nausea and vomiting in pregnancy: Associations with maternal gestational diet and lifestyle factors in the Norwegian Mother and Child Cohort Study. BJOG: An International Journal of Obstetrics and Gynaecology, 120(13), 1642-1653. https://doi.org/10.1111/14710528.12406

Clark, S. M., Costantine, M. M., \& Hankins, G. D. V. (2012). Review of NVP and $H G$ and Early Pharmacotherapeutic Intervention. 2012. https://doi.org/10.1155/2012/252676

Einarson, T. R., Piwko, C., \& Koren, G. (2013). Quantifying the global rates of nausea and vomiting of pregnancy: a meta-analysis. 20(2), 171-183.

Frawley, J., Adams, J., Steel, A., Broom, A., Gallois, C., \& Sibbritt, D. (2015). Women' s Use and Self-Prescription of Herbal Medicine during Pregnancy: An Examination of 1, 835 Pregnant Women. Women's Health Issues, 1-7. https://doi.org/10.1016/j.whi.2015.03.0 01

Heitmann, K., Holst, L., Lupattelli, A., Maltepe, C., \& Nordeng, H. (2015). Treatment of nausea in pregnancy: A crosssectional multinational web-based study of pregnant women and new mothers. BMC Pregnancy and Childbirth, 15(1). https://doi.org/10.1186/s12884-0150746-2

Holden, S. C., Gardiner, P., Birdee, G., Davis, R. B., \& Yeh, G. Y. (2015). Complementary and Alternative Medicine Use Among Women During Pregnancy and Childbearing Years. September, 261-269.

Jafari-Dehkordi, E., Hashem-Dabaghian, F., Aliasl, F., Aliasl, J., Taghavi-Shirazi, M., Sadeghpour, O., Sohrabvand, F., Minaei, B., \& Ghods, R. (2017). Comparison of quince with vitamin B6 for treatment of nausea and vomiting in pregnancy: A randomised clinical trial. Journal of Obstetrics and Gynaecology, 37(8), 1048-1052. https://doi.org/10.1080/01443615.2017 .1322046

Joulaeerad, N., Ozgoli, G., Hajimehdipoor, H., Ghasemi, E., \& Salehimoghaddam, 
F. (2018). Effect of aromatherapy with peppermint oil on the severity of nausea and vomiting in pregnancy: A singleblind, randomized, placebo-controlled trial. Journal of Reproduction and Infertility, 19(1), 32-38.

Kia, P. Y., Safajou, F., Shahnazi, M., \& Nazemiyeh, H. (2014). The effect of lemon inhalation aromatherapy on nausea and vomiting of pregnancy: A double-blinded, randomized, controlled clinical trial. Iranian Red Crescent Medical Journal, 16(3). https://doi.org/10.5812/ircmj.14360

Mahmoud, R., Ghani, A., Tawfik, A., \& Ibrahim, A. (2013). The Effect of Aromatherapy Inhalation on Nausea and Vomiting in Early Pregnancy: A Pilot Randomized Controlled Trial. 3(6), 10-22.

Modares, M., Besharat, S., F, R. K., Besharat, S., Mahmoudi, M., \& H, S. S. (2012). Effect of Ginger and Chamomile capsules on nausea and vomiting in pregnancy. 14(1), 46-51.

National Institute for Health and Care Excellence (NICE) (2013) 'Clinical Knowledge Summaries: Nausea/vomiting in pregnancy'.

Omidvar, S., Firouzbakht, M., Nikpour, M., \& Jamali, B. (2014). Comparison of ginger with vitamin B6 in relieving nausea and vomiting during pregnancy. $A Y U$ (An International Quarterly Journal of Research in Ayurveda), 35(3),

289.

https://doi.org/10.4103/0974-

8520.153746

Saberi, F., Sadat, Z., Abedzadeh-Kalahroudi, M., \& Taebi, M. (2013). Acupressure and ginger to relieve nausea and vomiting in pregnancy: A randomized study. Iranian Red Crescent Medical Journal, 15(9), 854-861. https://doi.org/10.5812/ircmj.12984

Saberi, F., Sadat, Z., Kalahroudi, M. A., \& Taebi, M. (2014). Effect of Ginger on
Relieving Nausea and Vomiting in Pregnancy: A. Nurs Midwifery Stud, 3(1), 1-6.

Sharifzadeh, F., Kashanian, M., Koohpayehzadeh, J., Rezaian, F., Sheikhansari, N., \& Eshraghi, N. (2018). A comparison between the effects of ginger, pyridoxine (vitamin B6) and placebo for the treatment of the first trimester nausea and vomiting of pregnancy (NVP). Journal of Maternal-Fetal and Neonatal Medicine, 31(19), 2509-2514. https://doi.org/10.1080/14767058.2017 .1344965

Srivastava JK, Shankar E, Gupta S. Chamomile: A Herbal Medicine of The Past With Bright Future. Mol Med Report HHS Author Manuscr. 2011;

Wiraharja, R. S., Rustam, S., \& Iskandar, M. (2011). Kegunaan jahe untuk mengatasi gejala mual dalam kehamilan. 10(3), 161-170.

Wise, J. (2016). Women with nausea and vomiting in pregnancy should be offered more support, say RCOG guidelines. 3509(June), 22-23. https://doi.org/10.1136/bmj.i3509

Wood, H., McKellar, L. V., \& Lightbody, M. (2013). Nausea and vomiting in pregnancy: Blooming or bloomin' awful? A review of the literature. Women and Birth, 26(2), 100-104. https://doi.org/10.1016/j.wombi.2012.1 0.001 